\title{
Review
}

International Archives of
Allergy
Immunology

Published online: September 5, 2013

DOI: $10.1159 / 000354543$

\section{World Allergy Organization Anaphylaxis Guidelines: 2013 Update of the Evidence Base}

\author{
F. Estelle R. Simons ${ }^{a} \quad$ Ledit R.F. Ardusso $^{b}$ Vesselin Dimov ${ }^{c}$ Motohiro Ebisawa $^{e}$ \\ Yehia M. El-Gamal ${ }^{f}$ Richard F. Lockey ${ }^{d}$ Mario Sanchez-Borges ${ }^{g}$ \\ Gian Enrico Senna ${ }^{\text {h }}$ Aziz Sheikhi Bernard Y. Thong ${ }^{j}$ Margitta Wormk \\ for the World Allergy Organization
}

\begin{abstract}
a Departments of Pediatrics and Child Health, and Immunology, Faculty of Medicine, University of Manitoba, Winnipeg, Man., Canada; b Cátedra Neumonología, Alergia e Inmunología, Facultad de Ciencias Médicas, Universidad Nacional de Rosario, Rosario, Argentina; 'Section of Allergy, Asthma and Immunology, Department of Pediatrics and Medicine, University of Chicago, Chicago, III., and d University of South Florida College of Medicine, Tampa, Fla., USA; 'Department of Allergy, Clinical Research Center for Allergy and Rheumatology, Sagamihara National Hospital, Sagamihara, Japan;

${ }^{f}$ Pediatric Allergy and Immunology Unit, Ain Shams University, Cairo, Egypt; ${ }^{9}$ Allergy and Clinical Immunology Department,

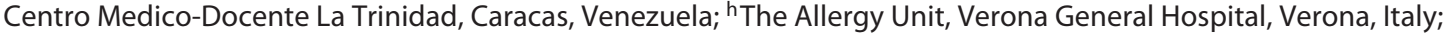
'Allergy and Respiratory Research Group, Center for Population Health Sciences, The University of Edinburgh, Edinburgh, UK; jDepartment of Rheumatology, Allergy and Immunology, Tan Tock Seng Hospital, Singapore; ${ }^{\text {k}}$ Allergie-Centrum-Charité, Klinik fur Dermatologie, Venerologie und Allergologie, Campus Charité Mitte, Universitätsmedizin, Berlin, Germany
\end{abstract}

\section{Key Words}

Anaphylaxis · Systemic allergic reaction · Epinephrine · Adrenaline $\cdot$ Auto-injector $\cdot$ Food allergy $\cdot$ Insect venom allergy · Drug allergy · Latex allergy · Exercise-induced anaphylaxis

\begin{abstract}
The World Allergy Organization (WAO) Guidelines for the assessment and management of anaphylaxis are a widely disseminated and used resource for information about anaphylaxis. They focus on patients at risk, triggers, clinical diagnosis, treatment in health care settings, self-treatment in the community, and prevention of recurrences. Their unique strengths include a global perspective informed by prior research on the global availability of essentials for anaphylaxis assessment and management and a global agenda for anaphylaxis research. Additionally, detailed colored illustrations are linked to key concepts in the text [Simons et al.: J Allergy
\end{abstract}

Clin Immunol 2011;127:593.e1-e22]. The recommendations in the original WAO Anaphylaxis Guidelines for management of anaphylaxis in health care settings and community settings were based on evidence published in peer-reviewed, indexed medical journals to the end of 2010. These recommendations remain unchanged and clinically relevant. An update of the evidence base was published in 2012 [Simons et al.: Curr Opin Allergy Clin Immunol 2012;12:389399]. In 2012 and early 2013, major advances were reported in the following areas: further characterization of patient phenotypes; development of in vitro tests (for some allergens) that help distinguish clinical risk of anaphylaxis from asymptomatic sensitization; epinephrine (adrenaline) research, including studies of a new epinephrine auto-injector for use in community settings, and randomized controlled trials of immunotherapy to prevent food-induced anaphylaxis. Despite these advances, the need for additional prospective studies, including randomized controlled trials of interventions in anaphylaxis is increasingly apparent. This

\section{KARGER}

E-Mail karger@karger.com

www.karger.com/iaa
(C) 2013 S. Karger AG, Basel

$1018-2438 / 13 / 1623-0193 \$ 38.00 / 0$
Correspondence to: Prof. F. Estelle R. Simons

Department of Pediatrics and Child Health and Department of Immunology Faculty of Medicine, University of Manitoba, Room FE125 820 Sherbrook Street, Winnipeg, MB R3A 1R9 (Canada)

E-Maillmcniven@ @sc.mb.ca 
2013 Update highlights publications from 2012 and 2013 that further contribute to the evidence base for the recommendations made in the original WAO Anaphylaxis Guidelines. Ideally, it should be used in conjunction with these Guidelines and with the 2012 Guidelines Update.

(c) 2013 S. Karger AG, Basel

\section{Introduction}

The World Allergy Organization (WAO) Guidelines for the Assessment and Management of Anaphylaxis (subsequently referred to in this publication as the "WAO Anaphylaxis Guidelines' or 'the Guidelines') were published in early 2011 [1]. The recommendations made in the Guidelines remain unchanged and relevant. In this 2013 Update, a resource intended for use in conjunction with the Guidelines and the 2012 Guidelines Update [2], we highlight major advances in anaphylaxis research published in 2012 and early 2013, thereby strengthening the evidence base for the recommendations made in the Guidelines [1].

Some of the unique aspects of the WAO Anaphylaxis Guidelines are summarized in table 1. These Guidelines were preceded by a survey of the global availability of essentials for the assessment and management of anaphylaxis. They focus on vulnerable patients, risk factors for severe or fatal anaphylaxis, and cofactors that amplify anaphylaxis. They include information on mechanisms and triggers. They emphasize prompt clinical diagnosis and prompt initial treatment that can be carried out even in a low-resource setting, as well as anticipatory longterm management of patients at risk of anaphylaxis recurrence [1].

In 2012, the WAO Anaphylaxis Guidelines and Guidelines-related materials such as posters and pocket cards that promulgate the main concepts of the Guidelines were widely disseminated (table 2). The posters and pocket cards were translated into many different languages [2]. In 2013, a patient information card based on the principles of prompt clinical diagnosis, prompt initial treatment, self-treatment in community settings, and prevention of recurrences was developed and disseminated $[1,3]$.

\section{Epidemiology of Anaphylaxis}

Retrospective studies of anaphylaxis have been reported from many countries and a variety of settings, including the community, allergy clinics, emergency departments (ED), hospital wards, and critical care units $[1,2$,
Table 1. Unique aspects of the 2011 WAO Anaphylaxis Guidelines

- Preceded by a published survey of global availability of essentials for assessment and management

- Provide a global perspective on anaphylaxis

- Developed in response to absence of global anaphylaxis guidelines $^{\mathrm{a}}$

- Developed without corporate funding

- Include evidence-based recommendations

- Cite 150 references, most published from 2006 to 2010 in indexed, peer-reviewed journals

- Include color illustrations linked to the key concepts in the text

- Highlight the role of the allergy/immunology specialist

- Propose a global agenda for anaphylaxis research

a ... and absence of national anaphylaxis guidelines in most countries; the WAO Anaphylaxis Guidelines were intended for use not only in countries without guidelines but also as an additional resource in countries with their own national guidelines. Adapted from Simons et al. [1].

Table 2. Dissemination of the WAO Anaphylaxis Guidelines and related materials

- Co-publication (open access) in: The Journal of Allergy and Clinical Immunology and in the World Allergy Organization Journal

- Posted on the WAO website and on WAO member society websites

- Summary posters and pocket cards translated into many languages $^{\text {a }}$

- Presented at meetings worldwide, including plenary sessions at AAAAI, EAACI, and WAO congresses

- Used in undergraduate and postgraduate medical courses

- Used in other specialty areas ${ }^{\mathrm{b}}$

- Used in primary care and allied health

- Update of the evidence base published in 2012 in Current Opinion in Allergy and Clinical Immunology

- Patient information card developed and disseminated in 2013

AAAAI = American Academy of Allergy Asthma and Immunology; EAACI = European Academy of Allergology and Clinical

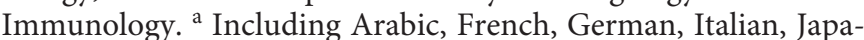
nese, Polish, Portuguese, Russian, Spanish, and Turkish. ${ }^{\mathrm{b}}$ Including sports medicine and the 2012 Olympics (by the Therapeutic Use Exemption Committee).

4-8]. These studies improve our understanding of anaphylaxis epidemiology and facilitate hypothesis generation. Analysis of standardized clinical data collected from a cohort of 2,012 adults and children with well-defined anaphylaxis is an important step forward and sets the stage for prospective studies [4]. 
Few epidemiologic studies to date have examined the incidence of anaphylaxis in the general population. Investigators in Spain used electronic medical records from primary care clinics, allergy clinics, ED visits, and hospitalizations, and tracked patients with anaphylaxis across different clinical settings. The incidence rate of 103 episodes per 100,000 person-years was higher than previously reported, with a peak of 314 episodes per 100,000 person-years in the age group 0-4 years [5].

Limited data have been published to date on the epidemiology of anaphylaxis in low- and middle-income countries. Investigators in Turkey used a novel 2-stage approach involving International Classification of Disease (ICD)-10 codes with additional analysis of clinical codes to extract data on patients admitted with a recorded primary diagnosis of anaphylaxis to all 45 hospitals in Istanbul. Overall, 1.95 cases of anaphylaxis per 100,000 person-years were reported, likely an underestimate [6].

In a 5-year retrospective study of all patients seen in the ED of a community hospital, involvement of multiple organ systems or a history of ED visits for anaphylaxis were among the factors contributing to higher admission rates [7].

Anaphylaxis admissions to UK critical care units are increasing year on year, constituting $0.1 \%$ of admissions to pediatric units and $0.3 \%$ of admissions to adult units. Survival rates are high, at over 90\% [8].

Anaphylaxis is sometimes difficult to diagnose postmortem [2]. Brazilian data call attention to the inadequacies of ICD-10 coding for ascertainment of death due to anaphylaxis [8]. Of 498 fatalities, $75 \%$ were definitely attributable to anaphylaxis according to established criteria [4]. In order to identify these deaths, the investigators had to consider information from both ICD-10 underlying cause of death fields and ICD-10 contributing cause of death fields. They recommended standardization of coding definitions in order to facilitate international comparisons and trend analyses [9].

\section{Patient Risk Factors}

As highlighted in previous WAO Anaphylaxis Guidelines publications $[1,2]$, for different reasons, infants, teenagers, pregnant women, and the elderly have increased vulnerability to anaphylaxis. Concomitant diseases, such as severe or uncontrolled asthma, cardiovascular disease, and mastocytosis, and concurrent use of some medications increase the risk of severe or fatal anaphylaxis $[1,2]$.

2013 Update: WAO Anaphylaxis Guidelines
Different anaphylaxis triggers (elicitors, causes) predominate in different age groups. Among 24,443 adults (mostly nonatopic, $80 \%$ female) with a mean age 42 years (range 16-83) admitted to a tertiary health care facility, 516 (2\%) were diagnosed with anaphylaxis. Drugs were by far the most common trigger ( $91 \%$ of cases) [10]. In contrast, in two ED studies in adults with an age of $51 \pm$ 16.9 years (mean \pm SD) [11] and 44.3 years (interquartile range 32-58) [12], respectively, food triggers were as common as drug triggers, followed by venom triggers.

Most infants and young children with anaphylaxis are atopic and most episodes in this age group are triggered by food. In a retrospective study of 371 infants, children, and teenagers with acute allergic reactions to food, the importance of underlying asthma was confirmed. During anaphylaxis, $72 \%$ of those with concomitant asthma had lower airway symptoms, compared with only $49 \%$ of those without concomitant asthma $(\mathrm{p}<0.01)$ [13].

Reports of fatal anaphylaxis to food have a similar pattern worldwide. In Israel, 4 young patients died after ingesting small amounts of milk $(n=3)$ or hazelnut $(n=1)$ to which they had previously experienced allergic reactions. Although all patients had concurrent asthma for which an inhaled bronchodilator had been prescribed, none were on a controller medication [14].

The relationship between mast cell activation disorders and anaphylaxis has been further elucidated [15]. In children with cutaneous mastocytosis, a combination of extensive skin involvement (more than $90 \%$ of body surface area) and elevated baseline serum total tryptase concentrations (mean $45.5 \pm 5.2 \mu \mathrm{g} / \mathrm{l}$ ) predicted severe mast cell mediator-related symptoms and signs requiring hospitalization and in some cases critical care unit admission [16].

The importance of systemic mastocytosis as a risk factor for severe Hymenoptera sting-induced anaphylaxis and venom subcutaneous immunotherapy (SCIT)-induced anaphylaxis cannot be overemphasized $[1,2,17$, 18]. The association between drug-induced anaphylaxis and undetected mast cell disease is not as strong; nevertheless, examination for skin signs of mast cell disorders and measurement of baseline tryptase concentrations is recommended in these patients [19]. Elevated baseline tryptase concentrations do not appear to be a risk factor for anaphylaxis from SCIT with airborne allergens [20].

An observational cohort study of patients with Hymenoptera venom anaphylaxis confirmed significant contributing factors to be: elevated baseline tryptase concentrations, older age, absence of urticaria or angioedema during anaphylaxis, and symptom onset within $5 \mathrm{~min}$ af-

Int Arch Allergy Immunol 2013;162:193-204 195 
ter a sting; however, in this study, no significant relationship with $\beta$-blocker use or angiotensin-converting enzyme (ACE) inhibitor use was identified [18].

In an ED study of anaphylaxis, use of any antihypertensive medication ( $\beta$-blocker, ACE inhibitor, calcium channel blocker, angiotensin-receptor blocker, or diuretic) was associated with severe episodes involving three or more organ systems, syncope, hypoxia, or hypotension, and increased likelihood of hospitalization. This association occurred independently of age, gender, preexisting lung disease, or suspected trigger [12].

Cofactors, many of which are patient related, are relevant in anaphylaxis $[1,2]$. The possibility of cofactor amplification of anaphylaxis should be considered when assessing reactions to foods, nonsteroidal anti-inflammatory drugs (NSAIDs), exercise, and alcohol [21]. Pollinosis has been identified as an external cofactor on the basis of peak hospital admissions for anaphylaxis during the tree pollen season $(\mathrm{p}=0.015)$ [13].

\section{Triggers and Mechanisms}

Descriptions of new anaphylaxis triggers and improved methods of confirming triggers suggested by the history of the episode have a prominent place in the 2013 Update, as in the 2012 Update [2].

\section{Food}

Children who were clinically reactive to peanut (including those with anaphylaxis) had higher specific $\operatorname{IgE}$ levels to Ara h 1, Ara h 2, and Ara h 3 than asymptomatic peanut-sensitized children did $(p<0.00001)$. Elevated specific IgE to Ara h 2 was the major contributor to accurate discrimination between clinical reactivity to peanut and asymptomatic sensitization to peanut $(99.1 \%$ sensitivity, $98.3 \%$ specificity, and $1.2 \%$ misclassification rate) and had a higher discriminative accuracy than IgE to whole peanut extract $(\mathrm{p}=0.008)$ [22].

Short-chain low molecular weight galacto-oligosaccharides with prebiotic effects that are added to some cow's milk formulas have been identified as a new trigger of IgE-mediated anaphylaxis in patients presenting at a median age of 6 years [23].

In tropical climates, orally ingested mites that contaminate wheat flour can trigger anaphylaxis even after cooking (the so-called 'pancake syndrome') and also play a role in food-dependent exercise-induced anaphylaxis [24].

In a prospective study, most patients allergic to red meat were sensitized to gelatin, and a subset was clini- cally allergic to both red meat and gelatin. The detection of galactose- $\alpha 1,3$-galactose ( $\alpha$-gal) in gelatin, and correlation between the results of $\alpha$-gal and gelatin testing, raised the possibility that $\alpha$-gal-specific IgE might be the target of reactivity to gelatin [25].

In a cross-sectional validation study in 99 fish-tolerant patients and 35 Anisakis simplex-allergic patients, in addition to use of commercially available allergens in skin prick tests and the ImmunoCap assay, testing with 5 recombinant Anisakis allergens (Ani s 1, Ani s 3, Ani s 5, Ani s 9, and Ani s 10) retained high diagnostic sensitivity and increased diagnostic specificity [26].

Anaphylaxis to food typically occurs after ingestion [1, 2]; however, it can also occur after skin contact with vomited food such as egg and milk [27], or inhalation of minute food particles; for example, sleeping on pillows stuffed with soy products can cause nocturnal anaphylaxis in soy-sensitized patients [28].

In wheat-dependent exercise-induced anaphylaxis, IgE antibodies to recombinant omega ${ }_{5}$-gliadin are detectable in more than $80 \%$ of patients. In their absence, it can be helpful to determine IgE reactivity to other wheat proteins such as $\alpha-\beta$ - $\gamma$-gliadin (especially $\gamma$-gliadin) and high molecular weight glutenin $[29,30]$.

\section{Venoms}

True double positivity to bee and vespid venoms is difficult to distinguish from cross-reactivity to these venoms [1]. Only $47 \%$ of 76 patients with double positivity to whole bee and wasp (yellow jacket) venoms reacted to recombinant species-specific major allergens (rSSMA) from both of these species. The specificity of IgE to rSSMA was excellent, especially for wasp venom [31]. In another study, component-resolved diagnosis with wasp-specific recombinant allergen components Ves $\mathrm{v} I$ and Ves $\mathrm{v} 5$ was a reliable method of diagnosing wasp/yellow jacket allergy [32].

\section{Drugs and Biologic Agents}

In a retrospective review, anaphylaxis comprised $6 \%$ of 16,157 adverse drug reactions and was reported in patients 7 days to 91 years old. Of these patients, $19 \%$ were hospitalized and 3\% died. Antibiotics, NSAIDs, antineoplastics/cytotoxic drugs, and immunomodulators were the most common triggers [33].

Proton pump inhibitor administration might increase the risk of developing any drug hypersensitivity. In 161 hospitalized patients, after controlling for confounders, the odds ratio of confirmed drug hypersensitivity was 4.35 (95\% CI 2.0-9.45) in those receiving a proton pump inhibitor compared with matched controls. A personal 
history of drug allergy and a long hospitalization time were also significant risk factors [34].

Some patients with clinical reactivity to paracetamol (acetaminophen) may have positive immediate skin tests to the drug, indicating involvement of specific IgE; however, negative skin tests do not exclude paracetamol hypersensitivity, which can also be mediated through leukotrienes or other mechanisms [35].

In a 10-year audit of anaphylaxis to muscle relaxants, $20 \%$ of 220 patients had positive intradermal tests to the muscle relaxant given during their surgical procedure, most commonly rocuronium or suxamethonium; $65 \%$ of those reacting to rocuronium and $29 \%$ of those reacting to suxamethonium had cross-reactivity to another muscle relaxant [36].

Biological agents are immunogenic and can cause anaphylaxis [1]. 'Immediate infusion reactions' attributed to rituximab, a common culprit, are usually attributed to cytokine release syndrome; however, rituximab can also be associated with anaphylaxis, rituximab-specific IgE, and rituximab-specific Th2 cells [37].

\section{Other Triggers}

In patients with a history of clinical reactivity to latex, latex-specific IgE assays remain useful, although they have a lower sensitivity than previously reported and should not be used for screening the general population [38]. In contrast, in patients with pollinosis who have no history of clinical reactivity to latex, commercially available latex-specific IgE assays are often positive but may not be clinically relevant [39].

Multiple food hypersensitivity was a hallmark of 82 Italian patients with food-dependent, exercise-induced anaphylaxis. When evaluated using skin prick tests, prickprick tests, and specific IgE levels, including an 89-allergen microarray, $96 \%$ were positive to one or more foods and $60 \%$ to more than 20 foods; $78 \%$ were positive to peach lipid transfer protein Pru p 3 [40].

Rarely, women develop anaphylaxis to human seminal plasma and human prostate-specific antigen [1]. Cross-reactivity of this allergen with the newly identified dog dander allergen Can $\mathrm{f} 5$ appears to be clinically relevant [41].

Based on a PubMed search, 4 genera of helminths are now reported to be associated with anaphylaxis. In addition to Echinococcus species and Anisakis species, these include Taenia solium cysticerosis and Ascaris species [42].

Anaphylaxis after skin contact with chemicals such as the persulfate in hair-bleaching products is rare, and the mechanisms have not yet been elucidated [43].

\section{Clinical Diagnosis}

Use of validated clinical criteria can be helpful in making the diagnosis of anaphylaxis [1-3]. Based on standardized data collected from 2,012 patients with severe respiratory or cardiovascular involvement in anaphylaxis, symptom profiles support the identification of patient risk factors, because they are impacted by age and comorbid disease in addition to triggers. In elderly patients, cardiovascular symptoms and medication or stinging insect triggers are typical. In young patients, respiratory symptoms, atopy, and food triggers are typical [5].

In a 10-year retrospective study, shock was documented in $41 \%$ of 294 patients with anaphylaxis, typically in elderly patients with initial symptoms of syncope, dizziness, and cyanosis after exposure to radiocontrast media or drugs. Patients without shock (59\% of the total) tended to be younger, had no initial cardiovascular symptoms, and reported food triggers [44].

In infants and children with anaphylaxis, hypotension is an uncommon initial manifestation [1], typically only occurring in severe episodes. During a prospective study of medically-supervised open food challenges in 80 children [median age 5.3 years (range 1.5-16)], a systolic blood pressure decrease greater than $30 \%$ was measured in only one child with anaphylaxis symptoms [45].

Uterine breakthrough bleeding and contractions can occur in women with anaphylaxis to honey bee venom, or to SCIT with honey bee venom. This is attributed to melittin, a venom component that interferes with complement cleavage and bradykinin release [46].

Clinical diagnosis of anaphylaxis is based on consideration of the patient's presenting symptoms and signs and on ruling out other sudden-onset multisystem diseases. The differential diagnosis includes common disorders such as acute asthma or acute urticaria [1,2]. It also includes uncommon disorders in which, as in anaphylaxis, delay in making an accurate diagnosis and initiating appropriate treatment can lead to death. As an example, in fatal attacks of hereditary angioedema due to C1-esterase inhibitor deficiency, the predyspneic phase lasts $3.7 \mathrm{~h}$ (range $0-11$ ); however, the dyspneic phase lasts only 41 min (range 2-240) and the loss of consciousness phase lasts only $8.9 \mathrm{~min}$ (range $0-20$ ) [47].

\section{Role of Laboratory Tests}

Results of laboratory tests performed on blood samples taken during anaphylaxis can be useful in some patients for subsequently confirming the diagnosis $[1,2]$. In a prospective study in adults, serum total tryptase con- 
centrations were measured sequentially $1-2,4-6$, and $12-$ $24 \mathrm{~h}$ after the onset of anaphylaxis symptoms and at baseline (follow-up). In $62 \%$ of the patients, initial tryptase levels were elevated (mean $19.3 \pm 15.4 \mu \mathrm{g} / \mathrm{l}$ ) with positive correlation between grades of severity and tryptase levels $(\mathrm{p}<0.001, \mathrm{r}=0.49)$ [48].

In early infancy, the normal reference range for baseline tryptase concentrations differs from the normal reference range in older infants, children, and adults. In nonatopic infants under 3 months of age, the median baseline tryptase concentrations were $6.1 \pm 3.5 \mu \mathrm{g} / \mathrm{l}$. In atopic infants under 3 months of age, the median baseline tryptase concentrations were $14.3 \pm 10.2 \mu \mathrm{g} / \mathrm{l}$. Levels gradually decreased during the first year of life, and by age 9-10 months, regardless of atopic status, median levels were $3.9 \pm 1.8 \mu \mathrm{g} / 1[1,49]$.

Transient elevation of platelet-activating factor (PAF) correlates better with anaphylaxis severity than tryptase or histamine concentrations do; however, PAF concentrations return to baseline within 15-20 $\mathrm{min}$ [50].

There are still no biomarkers or laboratory tests available for confirmation of the diagnosis of anaphylaxis at the time of presentation, and there are no biomarkers that are elevated regardless of the anaphylaxis trigger or its route of entry. Moreover, local mediator release without elevation of systemic levels of any biomarker might be important in some patients [1].

\section{Management of Anaphylaxis in Health Care Settings}

Prompt initial treatment is essential in anaphylaxis. Even a few minutes' delay can lead to hypoxic-ischemic encephalopathy or death. The importance of having a management protocol cannot be over-emphasized because retention of memorized facts and algorithms can be poor in a crisis and there is little or no time to look up information $[1,2]$.

The time-dependent and concentration-dependent pharmacologic effects of epinephrine (adrenaline) have been confirmed in a new in vitro human vascular smooth muscle cell model, in which early addition of epinephrine proved to be essential for inhibition of PAF-induced $\mathrm{PGE}_{2}$ release [51]. These findings are consistent with the clinical observation that epinephrine is maximally effective when injected promptly in anaphylaxis [1].

In a retrospective review of $321 \mathrm{ED}$ patients with anaphylaxis treated with epinephrine, need for two or more epinephrine injections did not correlate with obesity or overweight status; however, in an unspecified number of patients in this study, body mass index calculations were based on estimated height and weight rather than directly measured height and weight [52].

$\mathrm{H}_{1}$-antihistamines are not drugs of choice in initial anaphylaxis treatment because they do not relieve lifethreatening respiratory symptoms or shock, although they decrease urticaria and itching. The medications and doses used in anaphylaxis are extrapolated from urticaria treatment $[1,2]$. Intravenously administered $\mathrm{H}_{1}$-antihistamines can cause hypotension [53].

An updated Cochrane Database systematic review found no randomized or quasi-randomized controlled trials of glucocorticoid treatment for anaphylaxis, was unable to make definitive recommendations for or against their use, and highlighted the need for a more robust evidence base in this area [54]. Glucocorticoids remain in use for anaphylaxis because they potentially prevent biphasic anaphylaxis; however, medications and dosing are extrapolated from asthma treatment and the onset of action takes several hours. They are not drugs of choice in initial anaphylaxis treatment [1].

A discrepancy between anaphylaxis management recommendations in current guidelines and implementation of these recommendations was confirmed in a large ED study, in which only $12 \%$ of patients with severe anaphylaxis received epinephrine, although 50\% received an antihistamine and $51 \%$ received a glucocorticoid. Based on this data, a revised approach to training in anaphylaxis management was proposed [55].

The recommendation in the original WAO Anaphylaxis Guidelines for intravenous fluid resuscitation using the crystalloid normal saline, rather than a colloid, remains current [1]. A Cochrane review of randomized controlled trials of crystalloids versus colloids in thousands of surgical patients requiring volume replacement found that colloid administration did not correlate with increased survival [56].

In anaphylaxis refractory to initial treatment, new interventions are needed. Infusion of methylene blue, a selective inhibitor of the nitric oxide-cyclic guanosine monophosphate pathway, has been successful, especially in patients with distributive shock and profound vasodilation (vasoplegia) [57, 58].

\section{Vulnerable Patients}

In the treatment of vulnerable patients such as infants, pregnant women, and the elderly with anaphylaxis, small but important modifications of the management protocol for prompt initial treatment are needed 
[1]. As an example, pregnant women with anaphylaxis require not only prompt epinephrine injection but also high-flow supplemental oxygen, positioning on the left side so the gravid uterus does not compress the inferior vena cava and impede venous return to the heart, maintenance of systolic blood pressure at or above $90 \mathrm{~mm} \mathrm{Hg}$ to ensure adequate placental perfusion, and continuous electronic monitoring of both mother and infant. When cardiopulmonary resuscitation is indicated in a fully gravid woman, continuous chest compressions can be difficult. Emergency cesarean delivery is sometimes necessary [59].

\section{Long-Term Management: Self-Treatment in Community Settings}

After successful treatment of anaphylaxis in health care settings, patients should be equipped to treat recurrences that occur despite attempts to avoid trigger exposure in community settings $[1,2]$ (table 3 ).

In a prospective longitudinal observational study, advice and written instructions were provided to families of 512 milk- or egg-allergic infants who were age 3-15 months at study entry. During a median follow-up of 36 months, allergic reactions occurred in 53\% of the babies. Reactions were associated not only with misreading food labels or food cross-contamination but also with intentional exposure to foods that should have been avoided, and infants being fed by persons other than their parents. Of the $11.4 \%$ of infants with anaphylaxis, only $29.9 \%$ received epinephrine injections [60].

The annual incidence rate of accidental exposure to peanut in 1,411 at-risk children age $7.1 \pm$ SD 3.9 years was $13 \%$ over 1,175 patient-years (95\% CI 10.7-14.5). Children with a recent diagnosis, and adolescents, were at increased risk. Only $21 \%$ of moderate or severe allergic reactions were treated with epinephrine injections [61].

Patients at risk for anaphylaxis recurrence in community settings should be equipped with one or more epinephrine auto-injectors (EAI) [62]; if auto-injectors are unavailable or unaffordable, alternative (although not preferred) forms of injectable epinephrine should be recommended [1].

In the episodes of fatal anaphylaxis to foods described previously in this Update, the patients who died either had no EAI prescribed or did not have it available during their fatal episode [14].

Patterns of prescribing EAIs for patients at risk of anaphylaxis in community settings vary among allergists. As an example, although many anaphylaxis episodes after allergen SCIT begin after the typical 30-min on-site observation period in the clinic, for patients on SCIT, $13.5 \%$ of allergists never prescribe EAIs, 33.3\% always prescribe EAIs, and 52.7\% risk-stratify [63].

Persistence of acquired skills to treat anaphylaxis in community settings cannot be guaranteed by patient and caregiver training. Carrying EAIs and competency in using them have been documented to decrease with time after instruction [64].

A new EAI designed using human factors engineering principles has a compact $(9 \times 5 \times 1.5 \mathrm{~cm})$ shape and a single safety guard on the same end as the needle. It provides step-by-step audio instructions, a 5-second countdown during injection, and audio and visual confirmation when injection is complete [65]. Method of instruction and auto-injector size, shape, and preference to carry appear to be useful attributes [66].

Recognition of anaphylaxis symptoms and signs can sometimes be difficult, even for health care professionals [1]. In a blinded, cross-sectional online survey of a random sample of emergency medical service personnel, $99 \%$ of paramedics correctly identified a classic presentation of anaphylaxis; however, only 3\% recognized an atypical presentation of anaphylaxis in a patient with abdominal pain, hypotension, and no skin signs [67].

Progress in anaphylaxis education research continues. An educational curriculum for parents of children with food allergy that includes information on why, when, and how to use EAIs has been validated and is available online at no cost [68].

Pediatric allergists surveyed about when they typically begin to transfer responsibilities for anaphylaxis recognition and EAI use from adults to children and teenagers expected that by age 12-14 years their patients should begin to share these responsibilities. The allergists individualized the timing of transfer based on patient factors such as presence of asthma and absence of cognitive dysfunction [69]. Caregivers of children and teenagers at increased risk of anaphylaxis in community settings expected to begin gradual transfer of responsibilities earlier, to children age $<6-11$ years [70].

A 24-hour helpline established to provide access to expert management advice for food allergy-related anaphylaxis will potentially facilitate prompt epinephrine administration, improve clinical outcomes, and, when appropriate, provide reassurance [71].

Int Arch Allergy Immunol 2013;162:193-204 DOI: $10.1159 / 000354543$ 
Table 3. Recommendations for prevention and treatment of anaphylaxis recurrences at the time of discharge from the health care setting

Medication

- Self-injectable epinephrine/adrenaline from an auto-injector

- Self-injectable epinephrine from an ampule/syringe or prefilled syringe (alternative but not preferred formulations)

Other aspects of discharge management

- Anaphylaxis emergency action plan (personalized, written)

- Medical identification (e.g. bracelet, wallet card)

- Medical record electronic flag or chart sticker

- Emphasis on the importance of follow-up investigations, preferably by an allergy/immunology specialist ${ }^{\mathrm{a}}$

Assessment of sensitization to allergens

- Before discharge from the emergency department, consider measuring allergen-specific IgE levels in serum for assessment of sensitization to relevant allergens ascertained from the history of the anaphylactic episode

- At least 3-4 weeks after the episode, confirm allergen sensitization using skin tests to relevant allergens; if these tests are negative in a patient with a convincing history of anaphylaxis, consider repeating them weeks or months later

- Challenge/provocation tests, e.g. with food or medication, might also be needed in order to assess risk of future anaphylaxis episodes; tests should be conducted only in well-equipped health care settings staffed by trained, experienced professionals

Long-term risk reduction: avoidance and/or immune modulation

- Food-triggered anaphylaxis: strict avoidance of relevant food(s)

- Stinging insect venom-triggered anaphylaxis: avoidance of stinging insects; subcutaneous venom immunotherapy (protects $80-90 \%$ of adults and $98 \%$ of children against anaphylaxis from future stings)

- Medication-triggered anaphylaxis: avoidance of relevant medications and use of safe substitutes; if indicated, desensitization (using a published protocol) conducted in a health care setting, as described above

- Idiopathic anaphylaxis (anaphylaxis of unknown etiology: continue search for hidden or novel triggers; measure baseline tryptase concentrations to help identify mast cell activation disorders; consider glucocorticoid and $\mathrm{H}_{1}$-antihistamine prophylaxis for 2-3 months

Optimal management of asthma and other concomitant diseases

a Allergy/immunology specialists play a uniquely important role in preparing the patient for self-treatment in the community, confirmation of the etiology of an anaphylactic episode, education regarding allergen avoidance, and immune modulation. Adapted from Simons et al. [1]; please see this reference for details.

\section{Long-Term Management: Prevention of Recurrence}

\section{Risk Assessment}

Tests to confirm the etiology of an anaphylaxis episode are critically important because the trigger suspected by the patient is not necessarily the true culprit. The confirmed trigger needs to be strictly avoided if future episodes are to be prevented $[1,2]$ (table 3 ).

Children with suspected allergy to milk or egg, and a negative skin prick test, require a specific IgE measurement to the suspect allergen, and those with an absent or undetectable IgE level require a skin prick test with the allergen [72]. In appropriately selected patients, medically supervised oral food challenges are needed to confirm or refute clinical reactivity to food $[72,73]$; however, standardization of food challenges is needed [73].

For peanut and other well-characterized food allergens, the utility of skin prick tests and specific IgE levels is maximized by considering the degree of positivity of the test results in the context of the reaction history. Component testing that measures IgE binding to specific proteins within the food potentially adds important information to the risk assessment [74].

In a retrospective study, in $98.7 \%$ of 478 consecutive patients with a convincing history of anaphylaxis after Hymenoptera stings, simultaneous testing with 4 different concentrations of honey bee venom and wasp venom was reported to be tolerated well; $0.6 \%$ of patients had allergic reactions and $0.6 \%$ had vasovagal reactions [75].

Skin tests to neuromuscular blocking agents were found to have an excellent negative predictive value when used to select an alternative neuromuscular blocking agent for subsequent surgery [76].

After an anaphylaxis episode, it is standard practice to defer skin tests for at least 3-4 weeks [1]. This sometimes presents a problem (e.g. in patients with perioperative anaphylaxis whose surgery cannot be delayed). In a prospective study in 44 patients, skin tests were performed 
early ( $0-4$ days after the reaction during anesthesia) and late (4-8 weeks after). The overall agreement between early and late skin tests was $71 \%(\mathrm{p}=0.002)$. The odds ratio of obtaining a false-negative test $0-4$ days after the reaction was 3.3 versus later testing $(\mathrm{p}=0.09)$. The investigators noted that while early testing can be useful in some patients, it does not replace later testing [77].

\section{Risk Reduction}

In a prospective longitudinal observational study in which 293 children age 3-15 months with clinical reactivity to cow's milk were monitored regularly, 53\% became milk tolerant by a median age of 63 months [78]. In some children, however, resolution of clinical reactivity to cow's milk can take years longer, during which they remain at risk of fatal anaphylaxis [2].

Monocyte chemotactic protein 1 (MCP-1) and macrophage inflammatory protein 1- $\alpha$ (MIP-1- $\alpha$ ) levels are low in children with clinical allergy to cow's milk protein and increase during desensitization to cow's milk [79].

Randomized controlled oral immunotherapy (OIT) or sublingual immunotherapy (SLIT) trials with food allergens such as milk [80], egg [81], or peanut [82] have been conducted in carefully selected patients with well-characterized clinical reactivity and well-defined levels of allergen sensitization. Over many months, milligram doses of allergen are given in OIT; microgram doses are given in SLIT. During treatment, most patients experience symptoms such as itchy mouth and throat, lip swelling, cough, or abdominal pain and up to $20 \%$ drop out due to serious adverse effects including anaphylaxis. Temporary desensitization can be achieved and maintained as long as the food is ingested regularly; however, permanent immunologic tolerance has been difficult to demonstrate. New approaches, such as pretreatment with omalizumab followed by combined treatment with omalizumab and food AIT, are promising [83]; however, at this time, food allergen immunotherapy is still not ready for use outside the context of controlled trials approved by research ethics boards $[1,2]$.

A Cochrane systematic review confirmed that subcutaneous insect venom immunotherapy (VIT) (which can lead to immunologic tolerance [1]) effectively prevents future allergic reactions to insect stings and improves the quality of life. The risk of systemic reactions is low, although significant [84]. Rush initiation of VIT with $H y$ menoptera venom is associated with an increased risk of systemic reactions [2]; as an example, ultra-rush initiation ( 3 visits over 2 weeks) with ant venom increased the risk of objective systemic reactions versus semi-rush initiation (10 visits over 9 weeks $)(p<0.001)$ [85].

2013 Update: WAO Anaphylaxis Guidelines
In patients with anaphylaxis triggered by a medication that is essential for them, substitution of a medication from a different therapeutic class is recommended [1]. If this is not possible, desensitization to the culprit drug is indicated, using a published protocol, in a hospital setting under medical supervision $[1,2]$. Most published literature on drug desensitization pertains to immediate hypersensitivity reactions $[1,2]$. In the absence of controlled studies or an evidence-based review of desensitization in delayed hypersensitivity reactions (defined as onset more than $1 \mathrm{~h}$ after drug administration), experts have summarized their experience with regard to indications, selection criteria, contraindications, procedures, risks, and complications of desensitization for these reactions [86]. The definition of delayed used in this important paper might require further discussion.

Sugammadex, a cyclodextrin derivative used to reverse the intramuscular blockade produced by rocuronium, encapsulates rocuronium in an inclusion complex and removes it from the neuromuscular junction to the plasma. Sugammadex also rapidly reverses anaphylaxis to rocuronium, possibly by sequestering IgE-bound rocuronium. It is not known whether the rocuronium remains potentially allergenic in inclusion complex form [87].

Vaccines that prevent infectious diseases rarely trigger anaphylaxis [1]. Patients with this history should be evaluated with skin tests to the vaccine and its components. If test results are negative, the vaccine can be administered in usual dose(s) under observation. If test results are positive, it should be administered in graded doses under observation. Patients with egg allergy of any severity (but no history of reacting to the influenza vaccine itself) can receive annual injections of trivalent influenza vaccine with low ovalbumin content, given and observed for 30 min in a setting where anaphylaxis can be recognized and treated promptly. In these patients, although skin testing with the vaccine or dividing the dose is unnecessary, live attenuated influenza vaccines are not recommended [88].

\section{Conclusions}

As summarized in this Update, the evidence base for the recommendations for the assessment, management, and prevention of anaphylaxis made in the $2011 \mathrm{WAO}$ Anaphylaxis Guidelines is being strengthened year after year (table 4). Major advances in 2012 and early 2013 were: further characterization of patient phenotypes; development of in vitro tests (for some allergens) that help distinguish clinical risk of anaphylaxis from asymptom-

Int Arch Allergy Immunol 2013;162:193-204 
Table 4. Progress on the global agenda for anaphylaxis research since 2011

\begin{tabular}{|c|c|c|}
\hline Agenda item & Progress & References \\
\hline Description of patient-specific risk factors; development of instruments to quantify them & ++ & $2,4,10-21$ \\
\hline Validation of the clinical criteria for diagnosis & ++ & 2,3 \\
\hline Development of in vitro tests to distinguish clinical risk of anaphylaxis from asymptomatic sensitization & +++ & $\begin{array}{l}2,22,23,25,26, \\
29-32,37-41\end{array}$ \\
\hline $\begin{array}{l}\text { Epinephrine research [pharmacology, epidemiology, and RCTs (not placebo-controlled) of dose vs. dose } \\
\text { and route vs. route] }\end{array}$ & +++ & $\begin{array}{l}2,51,52,55 \\
60-66\end{array}$ \\
\hline RCTs of second-line medications such as $\mathrm{H}_{1}$-antihistamines or glucocorticoids & \pm & 2,54 \\
\hline RCTs of immune modulation to prevent anaphylaxis episodes & +++ & $2,79-85$ \\
\hline Anaphylaxis education & ++ & $1,2,64,68-71$ \\
\hline
\end{tabular}

RCT $=$ Randomized controlled trial $\pm=$ minimal $++=$ some $;++=$ good $;+++=$ excellent .

atic sensitization; epinephrine research including studies of a new EAI for use in community settings, and randomized controlled trials of OIT and SLIT to prevent foodinduced anaphylaxis. Despite these advances, additional prospective studies, including randomized controlled trials of interventions, are urgently needed for the diagnosis, treatment, and prevention of anaphylaxis.

\section{Acknowledgements}

We acknowledge the support of the WAO, and the assistance of Lori McNiven, Health Sciences Centre, Winnipeg, Man., Canada. We sincerely thank Jacqueline Schaffer for illustrating the Patient Information Card. We appreciate the contributions of Dr. M. Beatrice Bilo and Dr. Yu Okada.

\section{References}

1 Simons FER, Ardusso LRF, Bilo MB, El-Gamal YM, Ledford DK, Ring J, Sanchez-Borges M, Senna GE, Sheikh A, Thong BY, for the World Allergy Organization: World Allergy Organization guidelines for the assessment and management of anaphylaxis. J Allergy Clin Immunol 2011;127:593.e1-e22.

-2 Simons FER, Ardusso LRF, Bilo MB, Dimov V, Ebisawa M, El-Gamal YM, Ledford DK, Lockey RF, Ring J, Sanchez-Borges M, Senna GE, Sheikh A, Thong BY, Worm M, for the World Allergy Organization: 2012 Update: World Allergy Organization (WAO) guidelines for the assessment and management of anaphylaxis. Curr Opin Allergy Clin Immunol 2012;12:389-399.

-3 Sampson HA, Munoz-Furlong A, Campbell RL, Adkinson NF Jr, Bock SA, Branum A, Brown SGA, Camargo CA Jr, Cydulka R, Galli SJ, Gidudu J, Gruchalla RS, Harlor AD Jr, Hepner DL, Lewis LM, Lieberman PL, Metcalfe DD, O'Connor R, Muraro A, Rudman A, Schmitt C, Scherrer D, Simons FER, Thomas S, Wood JP, Decker WW: Second symposium on the definition and management of anaphylaxis: summary report - Second National Institute of Allergy and Infectious Disease/Food Allergy and Anaphylaxis Network Symposium. J Allergy Clin Immunol 2006;117:391397.
4 Worm M, Edenharter G, Rueff F, Scherer K, Pfohler C, Mahler V, Treudler R, Lang R, Nemat K, Koehli A, Niggemann B, Hompes S: Symptom profile and risk factors of anaphylaxis in Central Europe. Allergy 2012;67:691698.

5 Tejedor Alonso MA, Moro Moro M, Mugica Garcia MV, Esteban Hernandez J, Rosado Ingelmo A, Vila Albelda C, Gomez Traseira C, Cardenas Contreras R, Sanz Sacristan J, Hernandez Merino A: Incidence of anaphylaxis in the city of Alcorcon (Spain): a populationbased study. Clin Exp Allergy 2012;42:578589.

-6 Cetinkaya F, Incioglu A, Birinci S, Karaman BE, Dokucu AI, Sheikh A: Hospital admissions for anaphylaxis in Istanbul, Turkey. Allergy 2013;68:128-130.

7 Steele R, Camacho-Halili M, Rosenthal B, Davis-Lorton M, Aquino M, Fonacier L: Anaphylaxis in the community setting: determining risk factors for admission. Ann Allergy Asthma Immunol 2012;109:133-136.

8 Gibbison B, Sheikh A, McShane P, Haddow C, Soar J: Anaphylaxis admissions to UK critical care units between 2005 and 2009. Anaesthesia 2012;67:833-839.

-9 Tanno LK, Ganem F, Demoly P, Toscano CM, Bierrenbach AL: Undernotification of anaphylaxis deaths in Brazil due to difficult coding under the ICD-10. Allergy 2012;67:783-789.
10 Gelincik A, Demirturk M, Yilmaz E, Ertek B, Erdogdu D, Colakoglu B, Buyukozturk S: Anaphylaxis in a tertiary adult allergy clinic: a retrospective review of 516 patients. Ann Allergy Asthma Immunol 2013;110:96-100.

11 Beyer K, Eckermann O, Hompes S, Grabenhenrich L, Worm M: Anaphylaxis in an emergency setting - elicitors, therapy and incidence of severe allergic reactions. Allergy 2012;67:1451-1456.

12 Lee S, Hess EP, Nestler DM, Bellamkonda Athmaram VR, Bellolio MF, Decker WW, Li JTC, Hagan JB, Manivannan V, Vukov SC, Campbell RL: Antihypertensive medication use is associated with increased organ system involvement and hospitalization in emergency department patients with anaphylaxis. J Allergy Clin Immunol 2013;131:1103-1108.

13 Vetander M, Helander D, Flodstrom C, Ostblom E, Alfven T, Ly DH, Hedlin G, Lilja G, Nilsson C, Wickman M: Anaphylaxis and reactions to foods in children - a populationbased case study of emergency department visits. Clin Exp Allergy 2012;42:568-577.

14 Levy MB, Goldberg MR, Nachshon L, Tabachnik E, Katz Y: Lessons from cases of mortality due to food allergy in Israel: cow's milk protein should be considered a potentially fatal allergen. Isr Med Assoc J 2012;14:29-33. 
15 Valent P: Mast cell activation syndromes: definition and classification. Allergy 2013;68: 417-424.

-16 Alvarez-Twose I, Vano-Galvan S, SanchezMunoz L, Morgado JM, Matito A, Torrelo A, Jaen P, Schwartz LB, Orfao A, Escribano L: Increased serum baseline tryptase levels and extensive skin involvement are predictors for the severity of mast cell activation episodes in children with mastocytosis. Allergy 2012;67: 813-821.

-17 Alvarez-Twose I, Bonadonna P, Matito A, Zanotti R, Gonzalez-de-Olano D, Sanchez-Munoz L, Morgado JM, Orfao A, Escribano L: Systemic mastocytosis as a risk factor for severe Hymenoptera sting-induced anaphylaxis. J Allergy Clin Immunol 2013;131:614-615.

18 Stoevesandt J, Hain J, Kerstan A, Trautmann A: Over- and underestimated parameters in severe Hymenoptera venom-induced anaphylaxis: cardiovascular medication and absence of urticaria/angioedema. J Allergy Clin Immunol 2012;130:698-704.

$\checkmark 19$ Brockow K, Bonadonna P: Drug allergy in mast cell disease. Curr Opin Allergy Clin Immunol 2012;12:354-360.

20 Asero R, Farioli L, Pastorello EA: Baseline serum tryptase levels and adverse reactions to injection specific immunotherapy with airborne allergens: is there a relationship? Int Arch Allergy Immunol 2012;158:276-280.

-21 Cardona V, Luengo O, Garriga T, LabradorHorrillo M, Sala-Cunill A, Izquierdo A, Soto L, Guilarte M: Co-factor-enhanced food allergy. Allergy 2012;67:1316-1318.

22 Hong X, Caruso D, Kumar R, Liu R, Liu X, Wang G, Pongracic JA, Wang X: IgE, but not IgG4, antibodies to Ara $\mathrm{h} 2$ distinguish peanut allergy from asymptomatic peanut sensitization. Allergy 2012;67:1538-1546.

-23 Chiang WC, Huang Chiung-H, Llanora GV, Gerez I, Goh SH, Shek LPC, Nauta AJ, Van Doorn WA, Bindels J, Ulfman LH, Knipping K, Delsing DJ, Knol EF, Lee BW: Anaphylaxis to cow's milk formula containing shortchain galacto-oligosaccharide. J Allergy Clin Immunol 2012;130:1361-1367.

-24 Sanchez-Borges M, Suarez Chacon R, Capriles-Hulett A, Caballero-Fonseca F, Fernandez-Caldas E: Anaphylaxis from ingestion of mites: pancake anaphylaxis. J Allergy Clin Immunol 2013;131:31-35.

25 Mullins RJ, James H, Platts-Mills TAE, Commins S: Relationship between red meat allergy and sensitization to gelatin and galactose-alpha-1,3-galactose. J Allergy Clin Immunol 2012;129:1334-1342.e1.

-26 Caballero ML, Umpierrez A, Perez-Pinar T, Moneo I, de Burgos C, Asturias JA, Rodriguez-Perez R: Anisakis simplex recombinant allergens increase diagnosis specificity preserving high sensitivity. Int Arch Allergy Immunol 2012;158:232-240.

27 Chernin LR, Swender DA, Hostoffer RW, Tcheurekdjian H: Anaphylaxis secondary to contact with a vomited food allergen. Ann Allergy Asthma Immunol 2012;109:279.
Armentia A, Pineda F, Martin B, San Miguel A, Gil FJM, Puente Y, de Lecea C, Palacios R: Anaphylaxis caused by hidden soybean allergens in pillows. J Allergy Clin Immunol 2013; 131:228-230.

29 Hofmann SC, Fischer J, Eriksson C, Bengtsson Gref O, Biedermann T, Jakob T: IgE detection to alpha/beta/gamma-gliadin and its clinical relevance in wheat-dependent exercise-induced anaphylaxis. Allergy 2012;67: 1457-1460.

30 Takahashi H, Matsuo H, Chinuki Y, Kohno K, Tanaka A, Maruyama N, Morita E: Recombinant high molecular weight-glutenin subunit-specific IgE detection is useful in identifying wheat-dependent exercise-induced anaphylaxis complementary to recombinant omega-5 gliadin-specific IgE test. Clin Exp Allergy 2012;42:1293-1298.

- 31 Muller U, Schmid-Grendelmeier P, Hausmann $\mathrm{O}$, Helbling A: IgE to recombinant allergens Api m 1, Ves v 1, and Ves v 5 distinguish double sensitization from crossreaction in venom allergy. Allergy 2012;67:1069-1073.

32 Ebo DG, Faber M, Sabato V, Leysen J, Bridts $\mathrm{CH}$, De Clerck LS: Component-resolved diagnosis of wasp (yellow jacket) venom allergy. Clin Exp Allergy 2013;43:255-261.

33 Ribeiro-Vaz I, Marques J, Demoly P, Polonia J, Gomes ER: Drug-induced anaphylaxis: a decade review of reporting to the Portuguese Pharmacovigilance Authority. Eur J Clin Pharmacol 2013;69:673-681.

- 34 Ramirez E, Cabanas R, Laserna LS, Fiandor A, Tong H, Prior N, Calderon O, Medrano N, Bobolea I, Frias J, Quirce S: Proton pump inhibitors are associated with hypersensitivity reactions to drugs in hospitalized patients: a nested case-control in a retrospective cohort study. Clin Exp Allergy 2013;43:344-352.

35 Rutkowski K, Nasser SM, Ewan PW: Paracetamol hypersensitivity: clinical features, mechanism and role of specific IgE. Int Arch Allergy Immunol 2012;159:60-64.

36 Brereton A, Russell WJ: Anaphylaxis to muscle relaxants: an audit of ten years of allergy testing at the Royal Adelaide Hospital. Anaesth Intensive Care 2012;40:861-866.

- 37 Vultaggio A, Matucci A, Nencini F, Pratesi S, Petroni G, Cammelli D, Alterini R, Rigacci L, Romagnani S, Maggi E: Drug-specific Th2 cells and IgE antibodies in a patient with anaphylaxis to rituximab. Int Arch Allergy Immunol 2012;159:321-326.

38 Accetta Pedersen DJ, Klancnik M, Elms N, Wang ML, Hoffmann RG, Kurup VP, Kelly KJ: Analysis of available diagnostic tests for latex sensitization in an at-risk population. Ann Allergy Asthma Immunol 2012;108:9497.

39 Unsel M, Mete N, Ardeniz O, Sin A, Gulbahar O, Kokuludag A: Diagnostic value of specific IgE analysis in latex allergy. Int Arch Allergy Immunol 2012;158:281-287.
40 Romano A, Scala E, Rumi G, Gaeta F, Caruso C, Alonzi C, Maggioletti M, Ferrara R, Palazzo P, Palmieri V, Zeppilli P, Mari A: Lipid transfer proteins: the most frequent sensitizer in Italian subjects with food-dependent exercise-induced anaphylaxis. Clin Exp Allergy 2012;42:1643-1653.

41 Basagana M, Bartolome B, Pastor-Vargas C, Mattsson L, Lidholm J, Labrador-Horrillo M: Involvement of Can $\mathrm{f} 5$ in a case of human seminal plasma allergy. Int Arch Allergy Immunol 2012;159:143-146.

42 Minciullo PL, Cascio A, David A, Pernice LM, Calapai G, Gangemi S: Anaphylaxis caused by helminths: review of the literature. Eur Rev Med Pharmacol Sci 2012;16:1513-1518.

-43 Hoekstra M, van der Heide S, Coenraads PJ, Schuttelaar MLA: Anaphylaxis and severe systemic reactions caused by skin contact with persulfates in hair-bleaching products. Contact Dermatitis 2012;66:317-322.

44 Park HJ, Kim SH: Factors associated with shock in anaphylaxis. Am J Emerg Med 2012; 30:1674-1678.

45 Caffarelli C, Rico S, Rinaldi L, Povesi Dascola C, Terzi C, Bernasconi S: Blood pressure monitoring in children undergoing food challenge: association with anaphylaxis. Ann $\mathrm{Al}-$ lergy Asthma Immunol 2012;108:285-286.

46 Mingomataj EC, Bakiri AH: Episodic hemorrhage during honeybee venom anaphylaxis: potential mechanisms. J Investig Allergol Clin Immunol 2012;22:237-244.

47 Bork K, Hardt J, Witzke G: Fatal laryngeal attacks and mortality in hereditary angioedema due to C1-INH deficiency. J Allergy Clin Immunol 2012;130:692-697.

48 Sala-Cunill A, Cardona V, Labrador-Horrillo M, Luengo O, Esteso O, Garriga T, Vicario M, Guilarte M: Usefulness and limitations of sequential serum tryptase for the diagnosis of anaphylaxis in 102 patients. Int Arch Allergy Immunol 2013;160:192-199.

49 Belhocine W, Ibrahim Z, Grandne V, Buffat C, Robert P, Gras D, Cleach I, Bongrand P, Carayon P, Vitte J: Total serum tryptase levels are higher in young infants. Pediatr Allergy Immunol 2011;22:600-607.

50 Vadas P, Perelman B, Liss G: Platelet-activating factor, histamine, and tryptase levels in human anaphylaxis. J Allergy Clin Immunol 2013;131:144-149.

51 Vadas P, Perelman B: Effect of epinephrine on platelet-activating factor-stimulated human vascular smooth muscle cells. J Allergy Clin Immunol 2012;129:1329-1333.

-52 Rudders SA, Geyer BC, Banerji A, Phipatanakul W, Clark S, Camargo CA Jr: Obesity is not a risk factor for repeat epinephrine use in the treatment of anaphylaxis. J Allergy Clin Immunol 2012;130:1216-1218.

53 Ellis BC, Brown SGA: Parenteral antihistamines cause hypotension in anaphylaxis. Emerg Med Australas 2013;25:92-93.

54 Choo KJL, Simons FER, Sheikh A: Glucocorticoids for the treatment of anaphylaxis. Cochrane Database Syst Rev 2012;4:CD007596. 
-55 Grabenhenrich L, Hompes S, Gough H, Rueff F, Scherer K, Pfohler C, Treudler R, Mahler V, Hawranek T, Nemat K, Koehli A, Keil T, Worm M: Implementation of anaphylaxis management guidelines: a register-based study. PLoS One 2012;7:e35778.

56 Perel P, Roberts I, Ker K: Colloids versus crystalloids for fluid resuscitation in critically ill patients. Cochrane Database Syst Rev 2013; 2:CD000567.

57 Bauer CS, Vadas P, Kelly KJ: Methylene blue for the treatment of refractory anaphylaxis without hypotension. Am J Emerg Med 2013; 31:264.e3-e5.

58 Jang DH, Nelson LS, Hoffman RS: Methylene blue for distributive shock: a potential new use of an old antidote. J Med Toxicol 2013; DOI: $10.1007 / \mathrm{s} 13181$.

-59 Simons FER, Schatz M: Anaphylaxis during pregnancy. J Allergy Clin Immunol 2012;130: 597-606.

-60 Fleischer DM, Perry TT, Atkins D, Wood RA, Burks AW, Jones SM, Henning AK, Stablein D, Sampson HA, Sicherer SH: Allergic reactions to foods in preschool-aged children in a prospective observational food allergy study. Pediatrics 2012;130:e25-e32.

61 Nguyen-Luu NU, Ben-Shoshan M, Alizadehfar R, Joseph L, Harada L, Allen M, St-Pierre Y, Clarke A: Inadvertent exposures in children with peanut allergy. Pediatr Allergy Immunol 2012;23:133-139.

62 Sheikh A, Simons FER, Barbour V, Worth A: Adrenaline auto-injectors for the treatment of anaphylaxis with and without cardiovascular collapse in the community. Cochrane Database Syst Rev 2012;8:CD008935.

63 Gupta P, Gerrish PK, Silverman B, Schneider A: Current practices among allergists on writing self-injectable epinephrine prescriptions for immunotherapy patients. J Allergy Clin Immunol 2012;129:571-572.e1-e2.

-64 Topal E, Bakirtas A, Yilmaz O, Ertoy IH, Arga M, Demirsoy MS, Turktas I: A real-life study on acquired skills from using an adrenaline autoinjector. Int Arch Allergy Immunol 2013; 160:301-306.

- 65 Edwards ES, Edwards ET, Gunn R, Patterson $\mathrm{R}$, North R: Design validation and labeling comprehension study for a new epinephrine autoinjector. Ann Allergy Asthma Immunol 2013;110:189-193.

66 Camargo CA Jr, Guana A, Wang S, Simons FER: Auvi-Q versus EpiPen: preferences of adults, caregivers and children. J Allergy Clin Immunol: In Practice 2013;1:266-272.

67 Jacobsen RC, Toy S, Bonham AJ, Salomone JA 3rd, Ruthstrom J, Gratton M: Anaphylaxis knowledge among paramedics: results of a national survey. Prehosp Emerg Care 2012; $16: 527-534$.
8 Sicherer SH, Vargas PA, Groetch ME, Christie L, Carlisle SK, Noone S, Jones SM: Development and validation of educational materials for food allergy. J Pediatr 2012;160:651656.

69 Simons E, Sicherer SH, Simons FER: Timing the transfer of responsibilities for anaphylaxis recognition and use of an epinephrine auto-injector from adults to children and teenagers: pediatric allergists' perspective. Ann Allergy Asthma Immunol 2012;108: 321-325.

70 Simons E, Sicherer SH, Weiss C, Simons FER: Caregivers' perspectives on timing the transfer of responsibilities for anaphylaxis recognition and treatment from adults to children and teenagers. J Allergy Clin Immunol: In Practice 2013;1:309-311.

71 Kelleher MM, Hourihane JO, Dunngalvin A, Cullinane C, Fitzsimons J, Sheikh A: A 24-h helpline for access to expert management advice for food allergy-related anaphylaxis in children: protocol for a pragmatic randomised controlled trial. BMJ Open 2012; 2:e001282.

72 Mehl A, Niggemann B, Keil T, Wahn U, Beyer K: Skin prick test and specific serum IgE in the diagnostic evaluation of suspected cow's milk and hen's egg allergy in children: does one replace the other? Clin Exp Allergy 2012; 42:1266-1272.

73 Ludman S, Wassenberg J, Du Toit G, Fox AT, Lack G, Eigenmann PA: Paediatric oral peanut challenges: a comparison of practice in London and Western Switzerland. Allergy 2013;68:539-541.

74 Sicherer SH, Wood RA: Advances in diagnosing peanut allergy. J Allergy Clin Immunol: In Practice 2013;1:1-13.

75 Strohmeier B, Aberer W, Bokanovic D, Komericki P, Sturm GJ: Simultaneous intradermal testing with hymenoptera venoms is safe and more efficient than sequential testing. Allergy 2013;68:542-544.

76 Ramirez LF, Pereira A, Chiriac AM, BonnetBoyer MC, Demoly P: Negative predictive value of skin tests to neuromuscular blocking agents. Allergy 2012;67:439-441.

77 Lafuente A, Javaloyes G, Berroa F, Goikoetxea MJ, Moncada R, Nunez-Cordoba JM, Cabrera-Freitag P, D’Amelio C, Sanz ML, Gastaminza G: Early skin testing is effective for diagnosis of hypersensitivity reactions occurring during anesthesia. Allergy 2013;68: 820-822.

78 Wood RA, Sicherer SH, Vickery BP, Jones $\mathrm{SM}$, Liu AH, Fleischer DM, Henning AK, Mayer L, Burks AW, Grishin A, Stablein D, Sampson HA: The natural history of milk allergy in an observational cohort. J Allergy Clin Immunol 2013;131:805-812.e4.
79 Glez PP, Franco YB, Matheu V: MIP-1alpha, MCP-1, and desensitization in anaphylaxis from cow's milk. N Engl J Med 2012;367:282284.

80 Yeung JP, Kloda LA, McDevitt J, Ben-Shoshan M, Alizadehfar R: Oral immunotherapy for milk allergy. Cochrane Database Syst Rev 2012;11:CD009542.

81 Burks AW, Jones SM, Wood RA, Fleischer DM, Sicherer SH, Lindblad RW, Stablein D, Henning AK, Vickery BP, Liu AH, Scurlock AM, Shreffler WG, Plaut M, Sampson HA: Oral immunotherapy for treatment of egg allergy in children. N Engl J Med 2012;367:233243.

82 Fleischer DM, Burks AW, Vickery BP, Scurlock AM, Wood RA, Jones SM, Sicherer SH, Liu AH, Stablein D, Henning AK, Mayer L, Lindblad R, Plaut M, Sampson HA: Sublingual immunotherapy for peanut allergy: a randomized, double-blind, placebo-controlled multicenter trial. J Allergy Clin Immunol 2013:131:119-127.

-83 Nadeau KC, Kohli A, Iyengar S, DeKruyff RH Umetsu DT: Oral immunotherapy and antiIgE antibody-adjunctive treatment for food allergy. Immunol Allergy Clin North Am 2012;32:111-133.

84 Boyle RJ, Elremeli M, Hockenhull J, Cherry MG, Bulsara MK, Daniels M, Oude Elberink JNG: Venom immunotherapy for preventing allergic reactions to insect stings. Cochrane Database Syst Rev 2012;10:CD008838.

85 Brown SGA, Wiese MD, van Eeden P, Stone SF, Chuter CL, Gunner J, Wanandy T, Phillips M, Heddle RJ: Ultrarush versus semirush initiation of insect venom immunotherapy: a randomized controlled trial. J Allergy Clin Immunol 2012;130:162-168.

- 86 Scherer K, Brockow K, Aberer W, Gooi JHC, Demoly P, Romano A, et al. Desensitization in delayed drug hypersensitivity reactions an EAACI position paper of the Drug Allergy Interest Group. Allergy 2013;68:844-852.

87 Baldo BA, McDonnell NJ, Pham NH: The cyclodextrin sugammadex and anaphylaxis to rocuronium: is rocuronium still potentially allergenic in the inclusion complex form? Mini Rev Med Chem 2012;12:701-712.

88 Kelso JM, Greenhawt MJ, Li JT, Nicklas RA, Bernstein DI, Blessing-Moore J, Cox L, Khan D, Lang DM, Oppenheimer J, Portnoy JM, Randolph CR, Schuller DE, Spector SL, Tilles SA, Wallace D: Adverse reactions to vaccines practice parameter 2012 update. J Allergy Clin Immunol 2012;130:25-43. 